\begin{tabular}{lllllllllllllllllllllllllllllllll}
\hline$R$ & $E$ & $V$ & I & S & T & A & D & E & E & S & T & U & D & I & O & S & I & N & T & E & R & N & A & C & I & O & N & A & L & E & S
\end{tabular}

\title{
Hegemonics constraints: the implications of 11 September for American power
}

Evelyn Koh

\section{Terrorist use of weapons of mass destruction: how serious is the threat?}

Andrew O'Neil

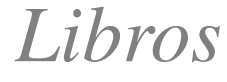

Australian Journal of International Affairs, Vol. 57, $\mathrm{N}^{\circ} 1$, abril 2003, pp. 77-112.

Tanto en el plano mundial como a nivel de los distintos países, la historia está marcada por grandes acontecimientos cuyas causas y proyecciones son materia de estudio para teorizadores e intérpretes de la historia, la sociología, la ciencia política y la economía. Al respecto, dos hitos recientes son, por un lado, los ataques del 11 de septiembre de 2001 y el consiguiente rediseño de la política exterior estadounidense y, por el otro, uno anterior pero susceptible de relacionar con el primero, como fue la caída del muro de Berlín y el posterior desmembramiento de la Unión Soviética. En cuanto a aquél, tal vez por su insanía o quizá porque pensamos que sus repercusiones nos atañen más directamente, ha movido a reflexión a legos y expertos; por su parte, el segundo tiene connotaciones que dan todavía para mucha literatura. Ambos permiten aventurar tesis sobre la evolución futura de la política mundial.

La autora del primer artículo en comento, Evelyn Goh, es Profesora Asistente del Instituto de Estudios Estratégicos y de Defensa de la Universidad de Nanyang, Singapur. A partir del su- 
puesto de que los ataques terroristas del 11 de septiembre no sólo no alteraron el predominio del poder estadounidense en el sistema internacional sino que fortalecieron su proyección en el extranjero, desarrolla la tesis de que la lucha contra el terrorismo requiere de medidas que vayan más allá del poderío militar y de que Washington necesita de la cooperación internacional. Sostiene que para obtenerla, su estrategia de seguridad debería considerar los alcances de su derecho a aplicar políticas unilaterales y fuerza militar, lo que no parece haber sido el caso. La verdad es que en el mundo posterior al 11 de septiembre rondan varias cuestiones críticas relacionadas con el poder estadounidense, desde su predominio sin precedentes, pasando por la forma en que lo ejerce hasta la forma en que es percibido en el resto del mundo, materias cuyo estudio a juicio de la señora Goh sería un aporte no sólo a la elaboración de esta estrategia sino también a su aplicación. No es difícil compartir su opinión de que el 11 de septiembre y la reacción de los Estados Unidos afectaron sus valores, su ideología y la impresión de legitimidad de su liderazgo, que serían las bases "blandas" de su poder y de que, a la larga, ello podría socavar la eficacia de su ejercicio del poder. Esto indicaría la conveniencia de que, al combatir el "nuevo" terrorismo, Estados Unidos utilizara su poder militar prudente y reflexivamente para evitar posibles consecuencias negativas de su acción.

Se ha reiterado ya bastante que los estadounidenses tomaron conciencia de su vulnerabilidad con incredulidad primero, luego con ira y finalmente con el deseo de demostrar la eficacia del poder de su país. Esto explicaría su apoyo a la acción unilateral de su país y al aumento del gasto en defensa. También es posible concordar con la autora en que un ataque no convencional como el sufrido demostró que el poder unipolar es tan vulnerable como el de cualquier otro Estado y que un desafío asimétrico como el del 11 de septiembre puede socavar las bases del poder de la gran potencia. y limitar su ejercicio, todo esto por supuesto con ciertos alcances. La guerra de los Estados Unidos contra el terrorismo indicaría que ha perdido algún terreno en el equilibrio de poder a nivel internacional, puesto que el resentimiento que provoca el que, para reafirmar su hegemonía, pueda actuar contra Estados relativamente impotentes indicaría claramente que debe hacer un gran esfuerzo diplomático para explicar y justificar su política exterior. Es cierto que, en general, Estados Unidos no es percibi- 
do como potencia amenazadora, entre otras razones porque adhiere a instituciones internacionales cuyas normas son compartidas por los demás Estados, pero el costo de su intervención en el mundo sería mayor si amigos o aliados no la apoyaran, o se opusieran a ella. Pese a que algunos académicos y analistas occidentales que se han mostrado renuentes a relacionar las prácticas de la política exterior estadounidense con la actividad terrorista antiamericana, algunos elementos de esa política podrían ser utilizados para promover la impresión de que los objetivos de su acción son víctimas y en consecuencia, podrían alentar la acción extremista en nombre de una "causa justa". Por ello, para reafirmar la legitimidad de sus intervenciones y su condición de liderazgo mundial, Washington debería comenzar por reexaminar y modificar sus políticas respecto del tercer mundo, de modo que ellas no se interpongan con el logro de la equidad, la justicia y la soberanía de pueblos que actualmente se encuentran marginados.

Dice la autora que para apreciar la legitimidad de la reacción de los Estados Unidos a los sucesos del 11 de septiembre y, en consecuencia, sus posibilidades de ser respaldada por los demás Estados, generalmente se ha recurrido a su medida más obvia, que es su respeto por las normas del derecho internacional. Para demostrar su afirmación, sostiene que la guerra contra el terrorismo plantearía dos cuestiones claves: el derecho al uso de la fuerza y los medios empleados al utilizarla. Destaca que se ha puesto en duda que pueda declararse la guerra contra un "ismo" de origen transnacional, de manifestación relativamente intangible y por naturaleza imposible de erradicar. Pensamos que ésta es una duda generalmente compartida, porque cuesta concebir una lucha contra un enemigo que no tiene parámetros determinables. Otro motivo de crítica han sido los límites del derecho a usar la fuerza y el supuesto objetivo de Bush de tomar represalias contra los Estados y regímenes que albergan a terroristas que, si bien se habrían justificado en el caso de Afganistán, no explican por qué Washington no ha procedido de igual manera con otros, que también constituyen un peligro para la seguridad mundial. Para algunos, al actuar contra Estados más débiles y de menor valor estratégico, Estados Unidos estaría satisfaciendo objetivos de una política de corto plazo. Una vez más, es posible coincidir con las dudas acerca de las verdaderas motivaciones de la gran potencia. 
El artículo de la señora Goh fue escrito antes de la última guerra contra Irak y ello explica su impresión de que la intervención de las Naciones Unidas habría moderado las acusaciones contra el unilateralismo de los Estados Unidos. Sin embargo, situándose todavía en terreno hipotético, añade que en el caso de actuar lo haría basándose en la doctrina de la acción preventiva, y que ello dejaba intactas las inquietudes relativas a la legitimidad de su hiperintervencionismo. A su juicio, el hecho de que Hussein sólo hubiera utilizado la fuerza contra vecinos débiles demostraba que carecía de estímulo para utilizar ADM contra Estados Unidos y sus aliados, por temor a las represalias. En este caso, un ataque preventivo sería la peor opción, puesto que lo obligaría a actuar precisamente de la manera que Washington deseaba evitar. A estas alturas, sabemos que la realidad se escribió de distinta manera y estas especulaciones pasaron a formar parte de la información a que echarán mano en el futuro quienes escriban la historia pasada; por ahora, no nos ayudan a hacer frente a las consecuencias de los hechos.

Otro campo importante relacionado con el tema de la hegemonía de Estados Unidos a que alude la señora Goh es el debilitamiento de su poder "blando"que, a diferencia del poder militar "duro", se basaría en sus valores e instituciones. La impresión de que Washington podría estar utilizando la excusa del antiterrorismo para perseguir otros objetivos estratégicos lleva a pensar que esos valores ceden ante un revisionismo del sistema internacional que los mismos Estados Unidos contribuyeron a formar. La autora subraya el hecho de que, para Estados Unidos, los aliados serían importantes no solo por razones políticas y diplomáticas "blandas", sino también por razones militares.

Todo apunta a la necesidad de ser prudentes al analizar las consecuencias de los ataques del 11 de septiembre y de evitar caer en la tentación de interpretar la política de Washington en función de la intención de restablecer el honor nacional tras la humillación de que fue objeto y no del genuino deseo de luchar contra el terrorismo. Si fuera así, la credibilidad e incluso la eficacia de los Estados Unidos podrían debilitarse debido a que la percepción que tengan sus aliados de las bases de su poder afectarA de manera decisiva su sustentabilidad. Bush ha explicitado su estrategia como una combinación de poder blando y duro para promover un "internacionalismo claramente americano que re- 
fleje la unión de nuestros valores y de nuestros intereses nacionales"; el problema radica en que la decisión de intervenir más asertivamente para proteger su seguridad y sus intereses podría exacerbar los problemas existentes, indicando que necesita más que nunca de aliados para poder resolver la contradicción entre su incontrarrestable predominio y su nueva vulnerabilidad.

Antes de que los Estados Unidos reconocieran abiertamente que la acción bélica contra Irak tuvo por objetivo derrocar el régimen de Saddam Hussein, las intenciones declaradas de la coalición que lideraban era librar al mundo del peligro de utilización de armas de destrucción masiva (ADM). Como ellas aún no se encuentran, cabe preguntarse si se justificaba destruir un país - y de paso infligir las graves consecuencias de este acto para las economías que en mayor o menor medida dependen para su desarrollo de los precios del petróleo -en función de meros temores. Junto con eso, cae de suyo reflexionar sobre el alcance de los peligros que representan estas armas de destrucción cuando están en manos de grupos terroristas y las posibilidades de que las utilicen, causando efectos devastadores en la civilización con el fin de promover ideologías fundamentalistas.

Por esta razón, el trabajo de Andrew O’Neil, académico de la Escuela de Estudios Políticos e Internacionales de la Universidad de Flinders, de Adelaida, resulta particularmente interesante. En efecto, tras reconocer que es difícil evaluar las amenazas de que es objeto la seguridad nacional, en especial aquéllas que plantea el terrorismo internacional, examina las posibilidades de que se produzcan ataques terroristas con armas nucleares, químicas o biológicas. Parte por señalar que a partir del término de la Guerra Fría ha aumentado significativamente el peligro de uso de ADM por grupos terroristas y ello por tres factores, a saber, el mayor acceso que podrían tener estos grupos a elementos para fabricar esta clase de armas que existen en el territorio de las repúblicas que formaban parte de la Unión Soviética; el surgimiento a escala mundial de una nueva clase de terrorismo, muchísimo más violento y despiadado que el conocido hasta ahora, y el hecho de que actualmente el terrorismo constituye un peligro incluso en lugares que antes se habían considerado libres de él. A juicio del autor, la especie de paranoia de que sólo es cuestión de tiempo antes de que haya ataques terroristas en gran escala con ADM, ha impedido analizar con objetividad la posibilidad de que materia- 
licen estos escenarios hipotéticos, cosa que se propone hacer al mismo tiempo que investiga si quizá podría haberse exagerado la amenaza que representan estas armas. Para ello, examina la posibilidad de que sean adquiridas por los terroristas, las probabilidades de que una vez adquiridas las utilicen y, finalmente, si el peligro ha aumentado después del 11 de septiembre de 2001.

En cuanto a las armas nucleares, debido a la dificultad para obtenerlas y a su elevado precio sólo estarían al alcance de los grupos terroristas más sofisticados. En consecuencia, si bien el peligro no puede descartarse totalmente, no serían motivo de preocupación inmediata. En cuanto a las armas químicas y biológicas, no obstante la mayor facilidad para acceder a los elementos principales y a la tecnología necesarios para fabricarlas, las segundas constituirían un escenario más probable, además de que son susceptibles de provocar mayor impacto psicológico en la población afectada.

El autor se pregunta luego si, aparte de fabricarlas, los grupos terroristas podrían obtener ADM por otros medios, como ser sustrayéndolas a quienes las o consiguiéndolas por conducto de Estados que simpaticen con sus mismos principios y objetivos. Le parece que difícilmente algún Estado estaría dispuesto a proporcionar esta clase de armas a entidades que no constituyan Estados.

Otro tema que aborda el autor es la posibilidad de que, en determinadas circunstancias, los grupos terroristas efectivamente opten por recurrir a las $\mathrm{ADM}$. Al respecto, algunos rechazan esta posibilidad y sostienen que pese a ser violentos, los terroristas son seres racionales y comprenden que un ataque con ADM que cause un elevado número de víctimas no les ayuda a propagar su ideología y puede incluso volverse contra ellos. En cambio, el profesor O`Neil considera que el peligro se torna cada vez más plausible, puesto que los grupos terroristas no operan con las mismas restricciones normativas de los Estados soberanos y el uso de ADM ilustraría su capacidad de infligir el máximo de daño a una potencia más fuerte, en el momento y lugar que deseen. El aspecto más importante que habría que tener en cuenta aquí serían las características del "nuevo" terrorismo, fenómeno complejo que persigue destruir tendencias mundiales que se contraponen a sus convicciones religiosas o políticas. Las razones por 
las cuales el peligro de que el terrorismo utilice ADM ha aumentado después de los ataques del 11 de septiembre de 2001 serían, primero, que estos demostraron la vulnerabilidad de sociedades abiertas como los Estados Unidos y segundo, que al establecer un nuevo hito, futuros grupos terroristas se verán tentados a tratar de superar la marca. De todos los razonamientos del autor, éste parece demasiado hipotético como para tenerlo seriamente en cuenta. El profesor O`Neil termina por preguntarse si, frente a estos peligros, la opinión pública estadounidense estará dispuesta a seguir apoyando los compromisos estratégicos globales de su país o bien, llegará a la conclusión de que los beneficios que acarrea la hegemonía americana son inferiores a los costos de ser blanco del terrorismo, en cuyo caso ejercería presión para que el país volviera a su política aislacionista.

La lectura cruzada de ambos artículos lleva a varias reflexiones. Ante todo, la prácticamente segura permanencia en el tiempo de la hegemonía de Estados Unidos - calculada al menos en cuarenta años- apunta a que, como país en desarrollo, muchas veces tendremos que optar entre los principios y la conveniencia inmediata, apreciada según el criterio de las autoridades del momento. Segundo, la vinculación con la potencia hegemónica nos acercará a peligros que ordinariamente habríamos considerado remotos. Tercero, la exportación de los métodos terroristas puede llegar hasta nuestro territorio y contribuir a exacerbar problemas propios y desestabilizar peligrosamente nuestro sistema. Cuarto, aunque de manera muy hipotética, un regreso al aislacionismo de Estados Unidos bajo la presión de la opinión pública puede echar por tierra los posibles efectos favorables de la globalización. Finalmente, aunque se menciona al pasar, no se ha apreciado en su cabal medida el efecto más letal de la acción terrorista, que es el efecto psicológico. En efecto, las armas causan muerte y destrucción, pero las ciudades se reconstruyen y los fallecidos pasan al terreno de los recuerdos, pero el pánico permanece y revive. Si no, hay que ver las imágenes del apagón reciente en Nueva York y preguntarse si hubo alguna persona que creyó, o cree todavía, que el hecho no guardó relación alguna con los ataques terroristas.

Rose Cave S. 